\title{
Intracranial Cavernomas: An Institutional Review
}

\author{
Vernon Velho ${ }^{1}$ Pravin Tukaram Survashe ${ }^{1} \quad$ Sachin Guthe ${ }^{1}$ \\ ${ }^{1}$ Department of Neurosurgery, Grant Government Medical College \\ and Sir J. J. Group of Hospitals, Mumbai, Maharashtra, India \\ Address for correspondence Pravin Tukaram Survashe, MCh, \\ Neurosurgery Department, J. J. Hospital Campus, Byculla, Mumbai, \\ Maharashtra 400008, India (e-mail: pravinsurvashe97@gmail.com).
}

Indian J Neurosurg 2016;5:89-94.

\begin{abstract}
Keywords

- cavernoma

- surgical excision

- intracranial

Introduction Intracranial cavernomas are rare vascular malformations accounting for 0.4 to $0.8 \%$ of all intracranial lesions. They usually present with seizures and neurological deficits following hemorrhagic episode. Surgical excision can provide lifetime cure from these lesions.

Aims and Objectives The aims and objectives of this study were to study the clinicopathological profile and discuss management strategies affecting the outcome of patients with intracranial cavernomas.

Materials and Methods We have studied patients of intracranial cavernomas operated in our department in the past 5 years. Magnetic resonance imaging of the brain was used as diagnostic modality of choice. Patients' clinical status upon admission and accessibility of the lesion were taken into account for surgical planning. Observation and Results Most of the patients were young. Twenty-two patients had single and 6 patients had multiple lesions. Patients with supratentorial lesions mainly presented with seizures $(75 \%)$ wherein infratentorial lesions had cranial nerve palsies and long tract signs (25\%). Total surgical excision was achieved in all the patients. No significant postoperative complications were encountered. None of the patient showed recurrence during follow-up period.

Conclusion Patients benefit from modern neurosurgical techniques in contrast to conservative approach in this disease of rather prolonged and unpredictable natural course.
\end{abstract}

\section{Introduction}

Cavernomas are the clusters of abnormal, hyalinized capillaries surrounded by hemosiderin deposits and a gliotic margin without intervening brain parenchyma. They are low-flow vascular malformations and contain blood products at various stages of evolution. The incidence of intracranial cavernoma is 0.4 to $0.8 \%$ in the general population. About 70 to $80 \%$ of them are located in supratentorial compartment, while 20 to $30 \%$ are in brain stem and cerebellum. Annual risk of hemorrhage is 0.7 to $1.1 \%$ per lesion for index bleed, while it increases to 4.5 to $5 \%$ per lesion for rebleeding. ${ }^{1-3}$ These are dynamic lesions which can grow, bleed, and regress. They are characterized by ongoing repeated intralesional microhemorrhages which leads to gradual impairment of patients' neurological function, not as dramatically as with hemorrhage due to arteriovenous malformations but often warrants surgical removal.

Magnetic resonance imaging (MRI) of the brain is the diagnostic modality of choice. $\mathrm{T}_{1}$-weightedand $\mathrm{T}_{2}$-weighted sequences show variable signals depending on the age of blood products. Popcorn appearance of the lesion is characteristic. It shows rim of signal loss due to hemosiderin deposition and prominent blooming on susceptibility-weighted sequences. However, most of the cavernomas are angiographically occult. ${ }^{4}$

Clinically, benign cavernomas are usually managed conservatively, while the symptomatic superficial lesions are dealt with microsurgical resection. Stereotactic radiosurgery is reserved for deeper lesions. However, conservative management cannot be relied on as natural history of these received

May 18, 2016

accepted

June 20, 2016

published online

August 27, 2016
DOI http://dx.doi.org/

10.1055/s-0036-1588031. ISSN 2277-954X.
(C) 2016 Neurological Surgeons' Society of India
License terms

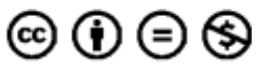


lesions is unpredictable. Stereotactic radiosurgery is also not promising as there is a persistent risk of bleeding and seizures. However, safe microsurgical excision of these lesions can dissipate the risk of bleeding and seizures. ${ }^{5-7}$ Hence, intracranial cavernoma is a surgically curable cause of epilepsy and cerebral hemorrhage.

\section{Aims and Objectives}

The aims and objectives of this study were to study the clinicopathological profile and discuss management strategies affecting the outcome of patients with intracranial cavernomas.

\section{Materials and Methods}

We did a retrospective study of 28 patients of intracranial cavernomas operated during January 2011 to December 2015. After thorough clinical examination, patients were subjected to computed tomography (CT) and MRI of the brain with contrast. Tractography and angiography were done wherever indicated. Based on clinical examination and radiological investigations, preoperative planning was done. Surgical approach was decided depending on location of the tumor. Total excision of cavernoma along with peripheral hemosiderin ring was done in all cases. Follow-up was done with MRI of the brain after 3 months and 1 year.

\section{Observations and Results}

The observations and results are shown (-Tables 1-9), and includes sex-wise distribution ( - Table 1 ), age-wise distribution ( - Table 2 ), clinical presentation ( - Table 3 ), number of lesions (-Table 4), location of the lesion (-Table 5 ), surgical approaches (-Table 6), extent of resection ( - Table 7 ),

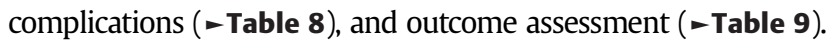

\section{Illustrated Cases}

\section{Case 1}

A 30-year-old man presented to OPD with complaints of headache, imbalance while walking and giddiness of 3 months duration. On clinical examination, he had features of left cerebellar ataxia. MRI of the brain was done which revealed mixed intensity lesions involving left cerebellum, right parietal region, and left centrum semiovale. As the patient was symptomatic with cerebellar lesion, it was excised surgically. Other two cavernomas were left behind. Symptomatic improvement is noted and patient is under regular follow-up (-Figs. 1-3).

Table 1 Sex-wise distribution

\begin{tabular}{|l|l|l|}
\hline & Number of patients & Percentage (\%) \\
\hline Male & 17 & 60 \\
\hline Female & 11 & 40 \\
\hline
\end{tabular}

Table 2 Age-wise distribution

\begin{tabular}{|l|l|l|}
\hline Age $(\mathrm{y})$ & Number of patients & Percentage $(\%)$ \\
\hline $1-9$ & 2 & 7 \\
\hline $10-19$ & 7 & 25 \\
\hline $20-29$ & 8 & 29 \\
\hline $30-39$ & 5 & 18 \\
\hline $40-49$ & 3 & 11 \\
\hline $50-59$ & 2 & 7 \\
\hline $60-69$ & 1 & 3 \\
\hline
\end{tabular}

Table 3 Clinical presentation

\begin{tabular}{|l|l|l|}
\hline Clinical presentation & $\begin{array}{l}\text { Number of } \\
\text { patients }\end{array}$ & Percentage (\%) \\
\hline Headache & 22 & 75 \\
\hline Seizures & 21 & 75 \\
\hline Focal neurological deficit & 7 & 25 \\
\hline Hemorhage & 7 & 25 \\
\hline
\end{tabular}

Table 4 Number of lesions

\begin{tabular}{|l|l|l|}
\hline & Number of patients & Percentage (\%) \\
\hline Single & 22 & 78 \\
\hline Multiple & 6 & 22 \\
\hline
\end{tabular}

Table 5 Location of the lesions

\begin{tabular}{|l|l|l|}
\hline Location & Number of patients & Percentage (\%) \\
\hline Supratentorial & 18 & 64 \\
\hline Infratentorial & 4 & 14 \\
\hline Combined & 6 & 22 \\
\hline
\end{tabular}

Table 6 Surgical approach

\begin{tabular}{|l|l|l|}
\hline Approach & $\begin{array}{l}\text { Number of } \\
\text { patients }\end{array}$ & Percentage (\%) \\
\hline $\begin{array}{l}\text { Frontal/parietal/temporal } \\
\text { craniotomy }\end{array}$ & 21 & 75 \\
\hline Retrosigmoid craniectomy & 4 & 14 \\
\hline $\begin{array}{l}\text { Midline suboccipital } \\
\text { craniectomy }\end{array}$ & 3 & 11 \\
\hline
\end{tabular}

Table 7 Extent of resection

\begin{tabular}{|l|l|l|}
\hline Extent of resection & $\begin{array}{l}\text { Number of } \\
\text { patients }\end{array}$ & Percentage (\%) \\
\hline Complete & 22 & 78 \\
\hline Incomplete & - & - \\
\hline $\begin{array}{l}\text { Residual asymptomatic } \\
\text { multiple cavernomas }\end{array}$ & 6 & 22 \\
\hline
\end{tabular}


Table 8 Complications

\begin{tabular}{|l|l|l|}
\hline Complications & $\begin{array}{l}\text { Number of } \\
\text { patients }\end{array}$ & Percentage (\%) \\
\hline Rebleeding & - & - \\
\hline Seizures & - & - \\
\hline New neurological deficit & 1 & 3 \\
\hline $\begin{array}{l}\text { Prolong ventilatory support } \\
\text { and tracheostomy }\end{array}$ & 2 & 6 \\
\hline Infection & - & - \\
\hline Death & - & - \\
\hline
\end{tabular}

Table 9 Outcome assessment

\begin{tabular}{|l|l|l|}
\hline Outcome parameter & $\begin{array}{l}\text { Number of } \\
\text { patients }\end{array}$ & Percentage (\%) \\
\hline Seizure control & $7 / 21$ & 33 \\
\hline Headache & $22 / 22$ & 100 \\
\hline $\begin{array}{l}\text { Focal neurological } \\
\text { deficit }\end{array}$ & - & - \\
\hline
\end{tabular}

\section{Case 2}

A 28-year-old man came with acute-onset right-sided weakness and abnormal deviation of face. On clinical examination, he had right hemiparesis (Power-MRC [Medical Research Council] Grade 2 in both upper and lower limbs with left facial paresis (LMN [lower motor neuron] type-House and Brackmann Grade 4). MRI of the brain was suggestive of two cavernomas in pontine and cerebellar peduncle region on either side, left side lesion showing evidence of hemorhage correlating with clinical presentation. It was targeted during surgery using neuronavigation. Complete excision achieved. Patient recovered gradually and presently under regular followup (-Figs. 4-7).

\section{Case 3}

A 34-year-old man presented with acute-onset right-sided weakness and convulsions. Neurologically, he had right- sided hemiparesis (Power-MRC Grade 2) with Glasgow coma scale 15/15 status. MRI of the brain revealed left parietal mixed intensity lesion with perilesional rim of hypointensity with blooming on gradient images. Lesion was localized with neuronavigation and completely excised along with perilesional bleed. Patient's power was Grade 2 in postoperative period and gradually improved in the physiotherapy follow-up period (-Figs. 8-10).

\section{Discussion}

Cavernous malformations are dilated thin-walled sinusoids covered by single layer of endothelium with undeveloped tight junctions. First report on cavernomas was given by Von Rokitanski in 1846, while first successful removal of cavernous angioma was reported by Bremer and Carson (1890). Natural evolution of cavernomas is totally unpredictable. Repeated hemorrhagic attacks and intractable seizures complicate the natural course. ${ }^{1-3}$ Microsurgical excision of these lesions virtually eliminates the risk of bleeding and seizures. Therefore, microsurgical excision is the definitive treatment in these cases. ${ }^{8}$

Our study encompasses 17 male and 11 female patients with ages ranging between 7 and 62 years. Most of the patients were young. Eighteen patients had supratentorial lesion, while 4 patients had cavernoma positioned in the infratentorial compartment; 6 patients had multiple cavernomas involving both the compartments. Patients with supratentorial lesions mainly presented with seizures (75\%), while patients with infratentorial lesion presented with cranial nerve palsies and long tract signs (25\%); $25 \%$ patients presented with acute hemorrhagic episode and undergone surgery in subacute period after hemorrhage (within 3 weeks).

For supratentorial lesions, keyhole craniotomy was done guided by neuronavigation and marker CT scan. Intraoperative ultrasound was used to accurately localize the lesion and confirm complete excision. Transsulcal approach was preferred. Identification of underlying cavernoma was done by adjacent yellowish discoloration of the brain tissue. Lesionectomy with excision of hemosiderin and gliotic ring was done in all the patients.

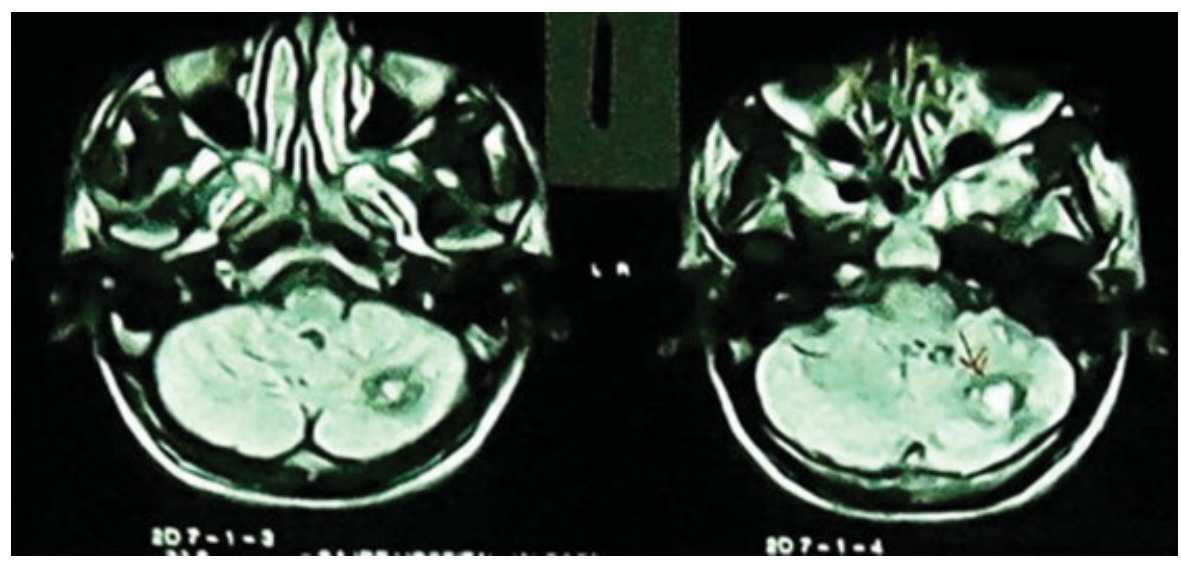

Fig. 1 T1-weighted axial image. 


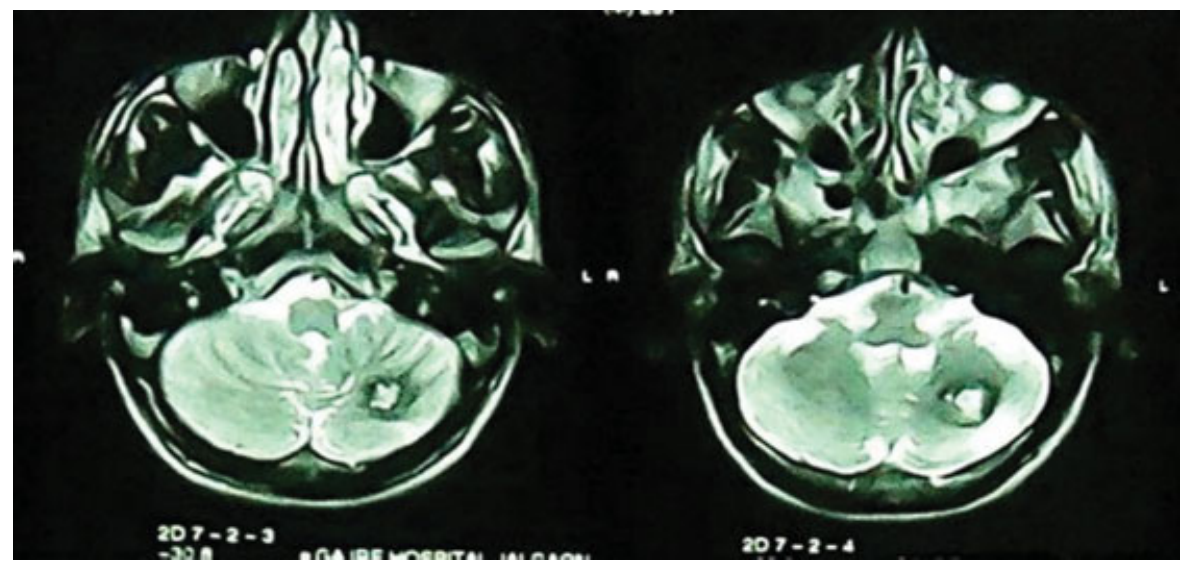

Fig. 2 T2-weighted axial image showing cavernous malformation in left cerebellar hemisphere.

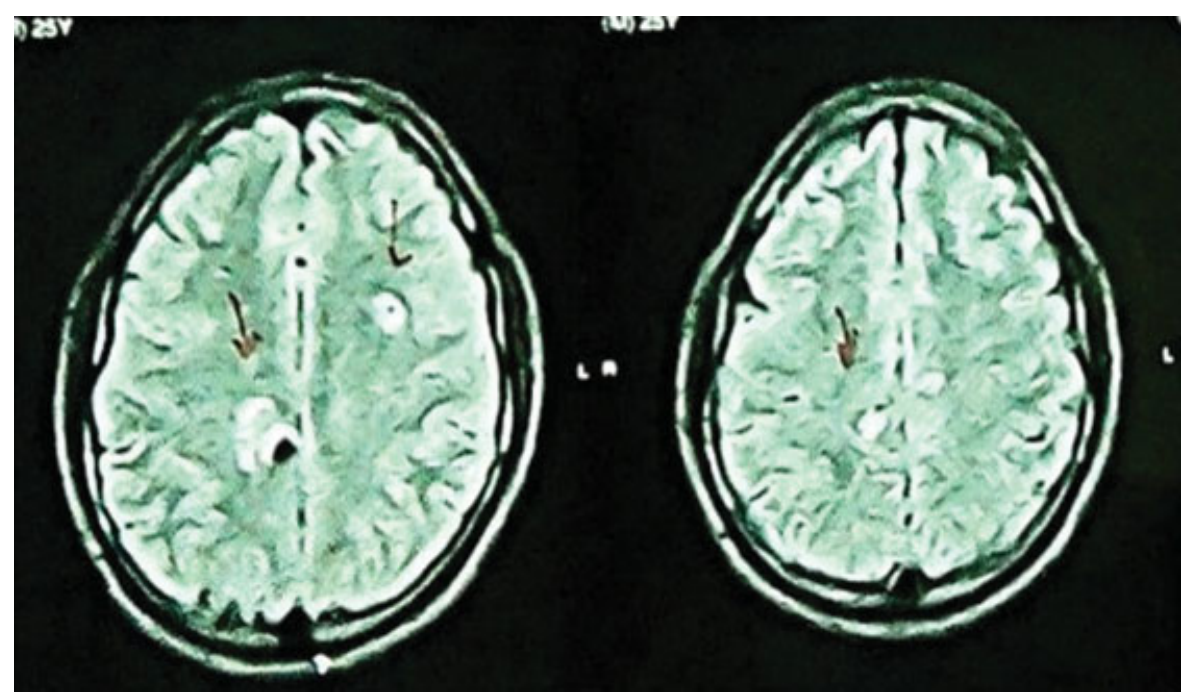

Fig. 3 Fluid-attenuated inversion recovery image showing right parietal and left frontal cavernoma.

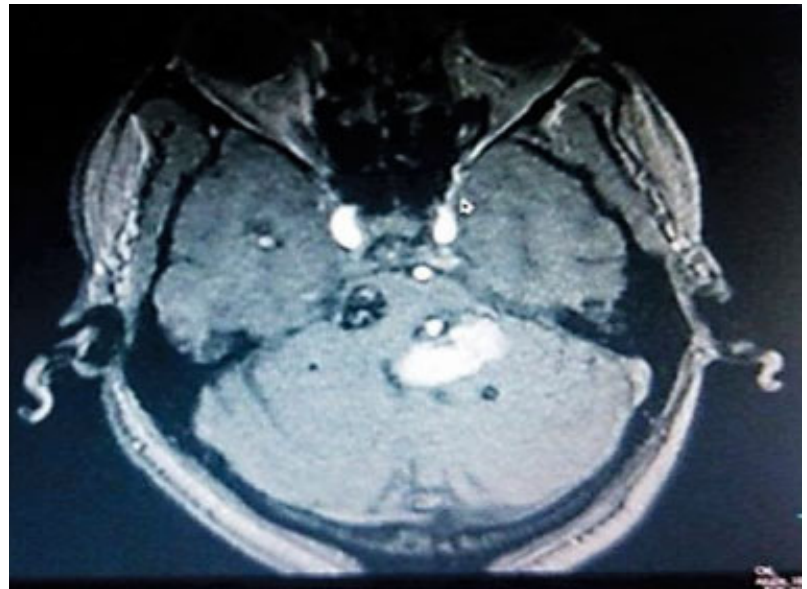

Fig. 4 T1-weighted axial image showing two cavernomas in pons and cerebellar peduncle region.

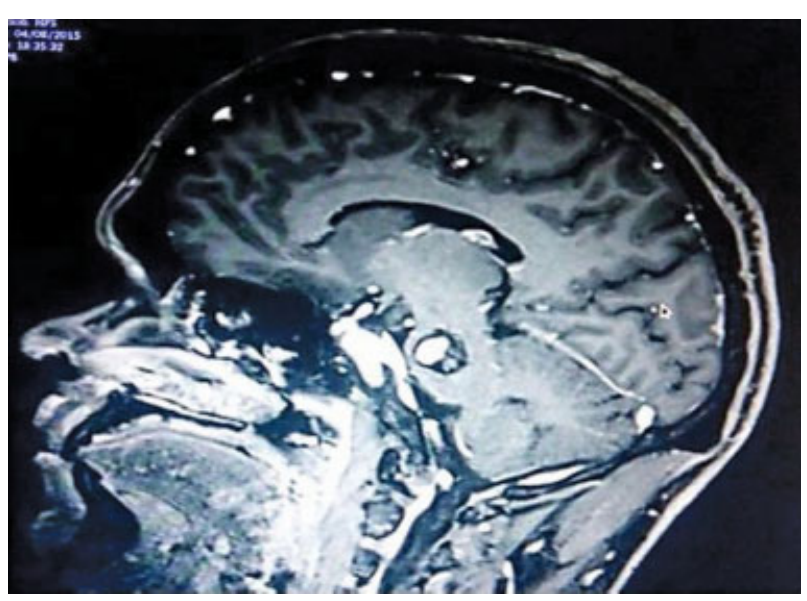

Fig. 5 T1-weighted sagittal image. 


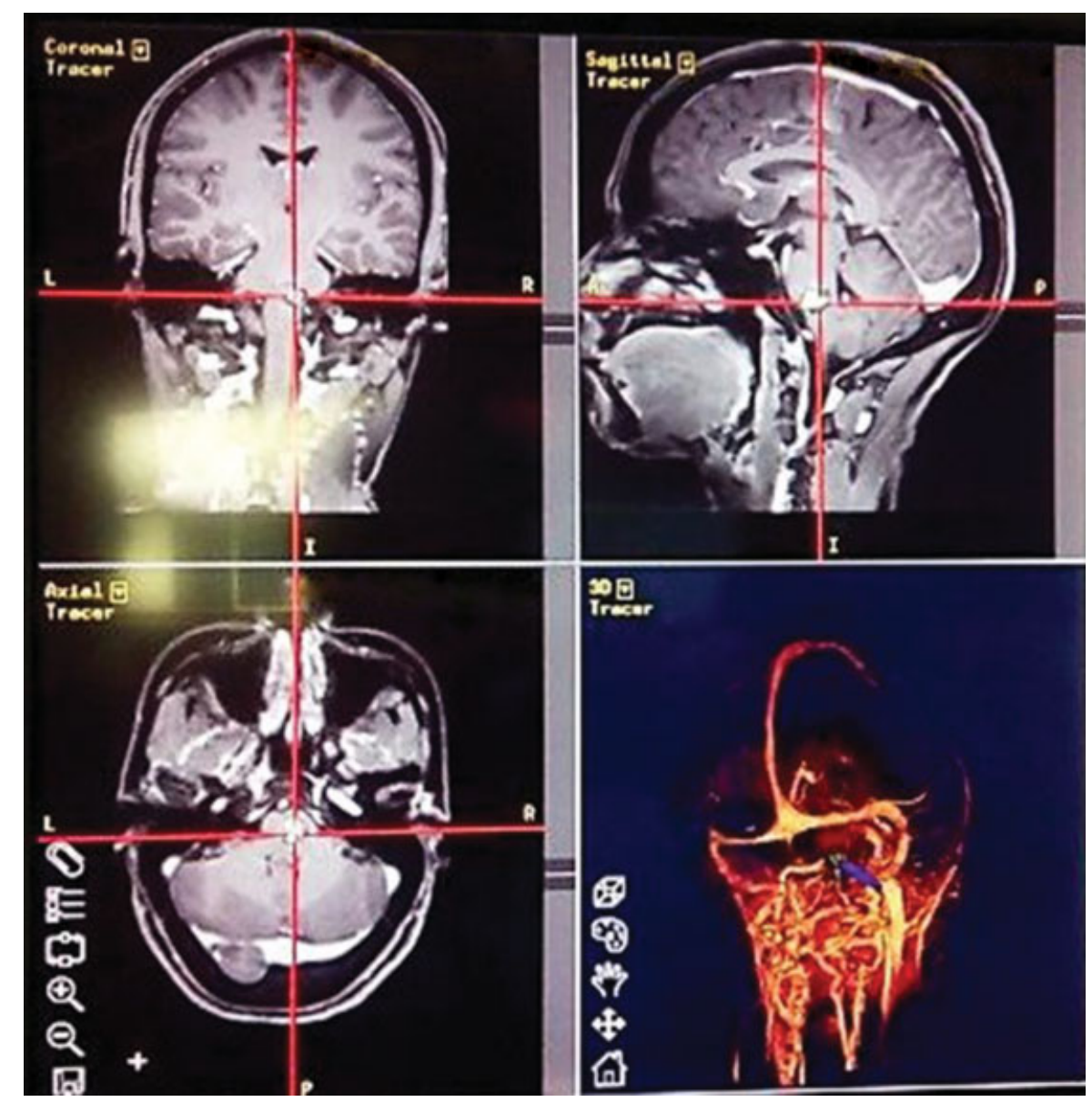

Fig. 6 Intraoperative neuronavigation image.

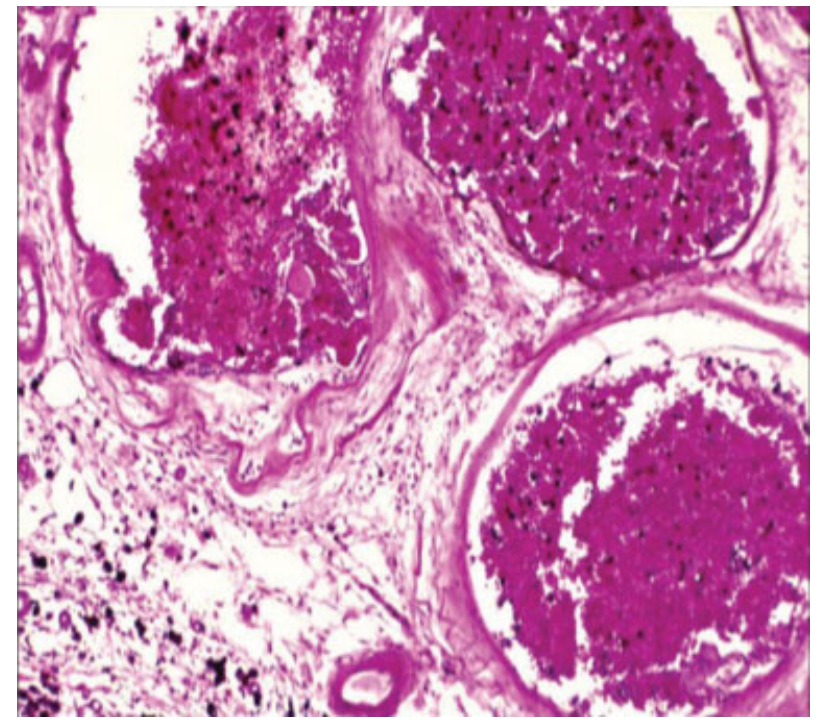

Fig. 7 Histopathological slide showing thinned out vascular parenchyma with intraluminal thrombus.

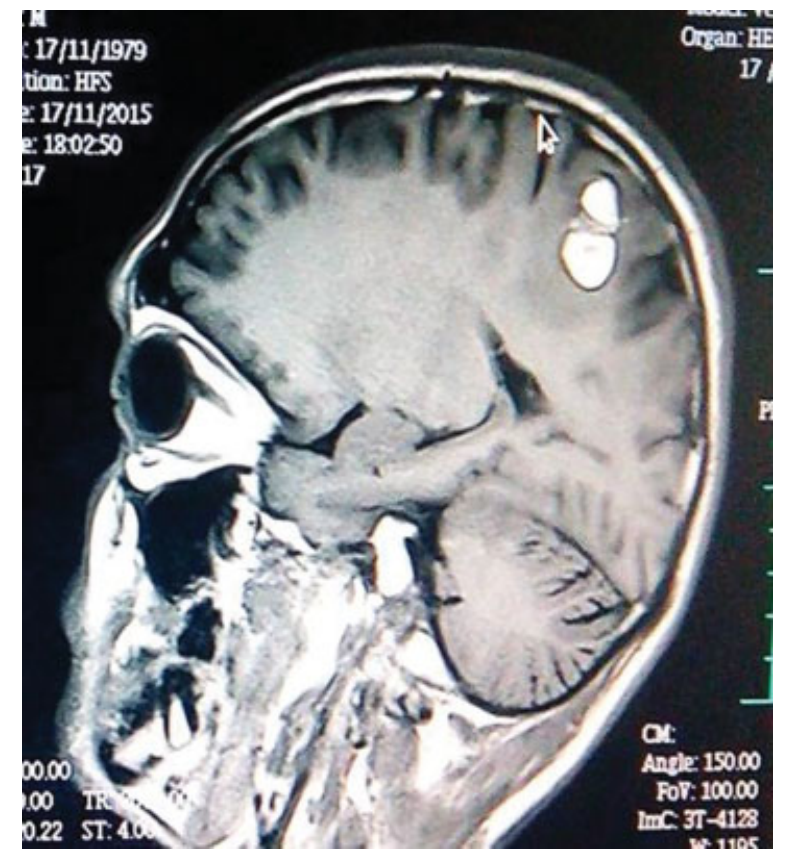

Fig. 8 T1-weighted image showing left parietal cavernoma localized on the motor strip. 


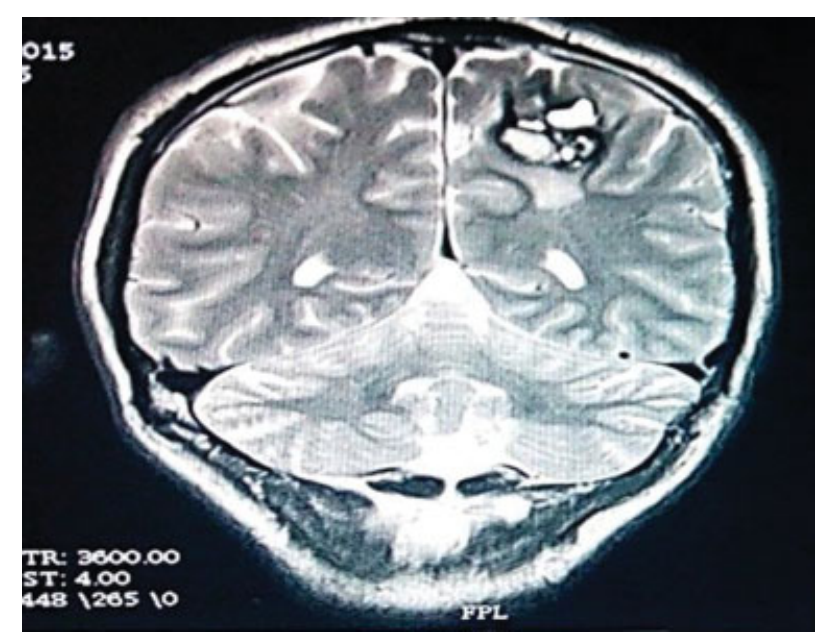

Fig. 9 T2-weighted image.

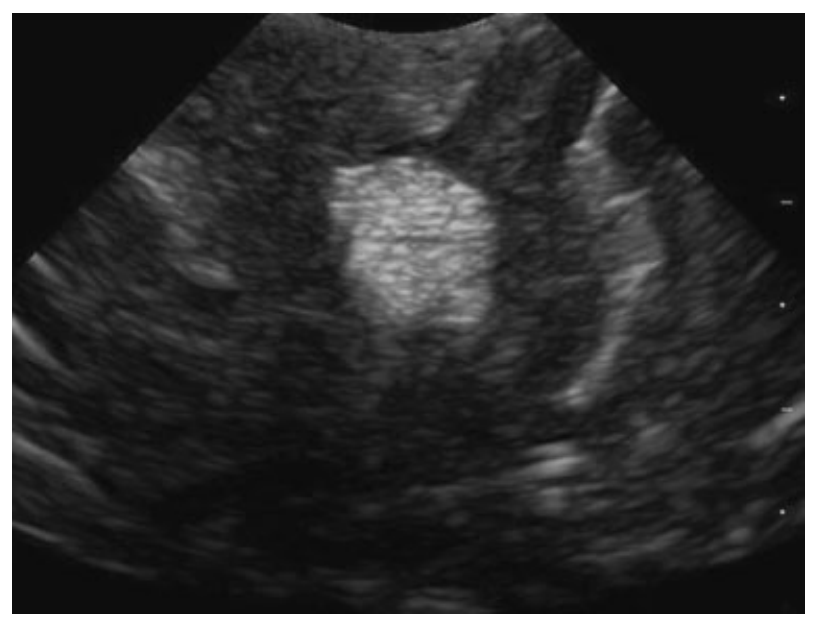

Fig. 10 Intraoperative ultrasound image.

In case of posterior fossa lesions, we had four brain stem lesions and three patients with cerebellar lesions. Regarding the approach, "shortest way to the lesions" was favored. Neuronavigation was used to pinpoint the lesion in brain stem.
Electrocoagulation shrinkage of the lesion followed by limited internal decompression and piecemeal removal was done.

Thus, total excision was achieved in all the patients. None of them had rebleeding. One patient with brain stem lesion developed additional neurological deficit in postoperative period. Two patients required prolong ventilation and tracheostomy. They were weaned off tracheostomy in 1 month. Follow-up MRI did not show recurrence in any of the patients. Out of 21 patients who presented with seizures, 7 patients became seizure free at the end of 1 year postoperatively.

\section{Conclusion}

Cavernomas represent an uncommon but surgically curable cause of epilepsy and cerebral hemorrhage. The use of neuronavigation and intraoperative ultrasound is useful tools in localizing the lesion and planning the approach.

\section{References}

1 Aiba T, Tanaka R, Koike T, Kameyama S, Takeda N, Komata T. Natural history of intracranial cavernous malformations. J Neurosurg 1995;83(1):56-59

2 Del Curling O Jr, Kelly DL Jr, Elster AD, Craven TE. An analysis of the natural history of cavernous angiomas. J Neurosurg 1991; 75(5):702-708

3 Kondziolka D, Lunsford LD, Kestle JRW. The natural history of cerebral cavernous malformations. J Neurosurg 1995;83(5):820-824

4 Rigamonti D, Drayer BP, Johnson PC, Hadley MN, Zabramski J, Spetzler RF. The MRI appearance of cavernous malformations (angiomas). J Neurosurg 1987;67(4):518-524

5 Kondziolka D, Lunsford LD, Flickinger JC, Kestle JR. Reduction of hemorrhage risk after stereotactic radiosurgery for cavernous malformations. J Neurosurg 1995;83(5):825-831

6 Maraire JN, Awad IA. Intracranial cavernous malformations: lesion behavior and management strategies. Neurosurgery 1995;37(4):591-605

7 Barrow DL, Schuette AJ. Cavernous malformations: a paradigm for progress. Clin Neurosurg 2011;58:27-41

8 Casazza M, Broggi G, Franzini A, et al. Supratentorial cavernous angiomas and epileptic seizures: preoperative course and postoperative outcome. Neurosurgery 1996;39(1):26-32, discussion 32-34 